\title{
Management Innovation in Chinese Context: The Diffusion of TQM in China
}

\author{
Xiaoqian Huang, Danyang Gao, Meijuan Wang \\ Department of Business Administration, School of Economics and Management, Huazhong Agricultural \\ University, Wuhan, China \\ Email: HXQzhn0904@163.com
}

Received 25 February 2016; accepted 28 March 2016; published 31 March 2016

Copyright @ 2016 by authors and Scientific Research Publishing Inc.

This work is licensed under the Creative Commons Attribution International License (CC BY). http://creativecommons.org/licenses/by/4.0/

(c) (i) Open Access

\begin{abstract}
This research focuses on the diffusion of TQM from 1978 in China when it began to reform and open up, and this paper has further discussed the features of management innovation in the Chinese context, which would have some inspirations for how to import a new management technique in a different context in the future research. The study found that from 1978 the dominant body of demand for management innovations has gradually shifted from government to enterprises and during different periods it shows differences in rationality. In China, the early discussion on TQM was first initiated by academic scholars who were usually deemed more rational than corporate managers, then it was affected by social psychological factors showing the other side of irrationality. Through bibliometric analysis of publications and journals on TQM, this study also found that the life cycles of the diffusion of management innovation were different when the dominant body of demand had changed.
\end{abstract}

\section{Keywords}

Management Innovation, Management Fashion, TQM, Bibliometrics

\section{Introduction}

Ever since the Austrian economist Schumpeter first introduced the definition of innovation in 1912, it has been referred and applied in almost every research area. Innovation is an important element to promote economic evolution (Schumpeter, 1961 [1]). As Stata (2004) [2] also pointed that an economy's growth potential is greatly determined by its innovation ability, the discussion on innovation in economy has never been "out". As the research on innovation in the west economic research area went deeper, it gradually developed into two important research directions: technical innovation and management innovation. In 1960s, many new technologies were 
invented and research on innovation had been mostly around technological innovation. It was until in the 1980s that management innovation had been given much attention it deserved. When Stata was doing a research on the factors that hindering innovation in an organization, he found that it was management not technology or creativity that restrained the development of organizations. Therefore, besides technical innovation, management innovation can also contribute a lot in economic growth, as Li Zinai (2002) [3] analyzed quantitatively the data collected from 1978 to 1998 in China finding that the economic growth volume caused by management innovation was about two times greater than technical innovation. Since the research on management innovation started in late years, perception on the construct of it hadn't reached common consensus. About the different definitions of management innovation, Bao Yuze et al. (2013) [4] had compared their differences in four aspects: research objects, perception on "new", implementation and intentions. In this study, the perception on "new" should be first clarified. For some researchers like Abrahamson, Birkinshaw and Kimberly, they considered that management innovation should study the new management techniques that are totally original and new to the whole world, while other scholars think that "new to an organization" is already enough, such as the introduction of TQM in Chinese enterprises should be also included in the research area of management innovation. Thus, two types of management innovation can be distinguished here; the former is the original type management innovation and the latter is imported type. Most western scholars were inclined to study the original type and insisted that it indicated great breakthrough in management knowledge thus having much more research values. While in China, the modern management system had been barely recognized and established in 1980s and in reality much advanced management theories had been imported from developed countries and introduced in China. Therefore for the present, to study the imported type has great practical value for China in introducing new management skills. This paper agrees with the definition of management innovation put forward by Chinese scholars Su Jingqin and Lin Haifen [5] in 2010: According to the specific problems faced by the organization and its internal and external environment, we should create or improve existing management philosophy or practice, process, skills and structures to achieve a more efficient use of resources and improve continuously organizational efficiency and performance.

The British Scholar Birkinshaw (2008) [6] summarized in his review of management innovation that there were generally four perspectives on the study of it: institutional perspective, fashion perspective, cultural perspective and rational perspective. Representatives of each perspective went deep in different core questions. The institutional perspective concerned about what institutional conditions lead to the emergence and diffusion of management innovation; the fashion perspective followed how the aspects of the supply of and demand for new management ideas affect their propagation; the cultural perspective thought about how management innovation shape and get shaped by organizational culture and the rational perspective considered the role of managers in inventing and implementing new management practices. As the classification of four perspectives put forward by Birkinshaw indicated, research on "management fashion" can be categorized as the fashion perspective of management innovation.

TQM was recognized as "management fashion" by many scholars who tried to define its diffusion process. Abrahamson, almost the founder of management fashion theory, started his research from the diffusion problem of innovation in 1991. He borrowed the term "fashion" from aesthetics and applied it in management study to explain the phenomenon that the emerging new management techniques are fanatically pursued in a certain period. In 1996, Abrahamson [7] defined in his paper "A management fashion is a relatively transitory collective belief, disseminated by management fashion setters that a management technique leads rational management progress". Some in-depth researches on management fashion were mainly carried out by foreign scholars in foreign context and institution, domestic research on this subject in China was inadequate and lack novelty. The systematic research abroad was mainly from two perspectives, the perspective of supply and demand and the perspective of life cycle.

From 1978 when TQM was first introduced in China, domestic discussion on it was quite numerous, but most of the research was from the micro level. Exploration from the macro or meso level like the diffusion in society was not enough. Here in this paper we tried to figure out some questions below: firstly, as an imported-type management innovation or management fashion, what kind of distinctive features would be shown in domestic context? Secondly, main study on management innovation was mostly based on the rational perspective, while management fashion involved irrational psychological factors, how does rationality and irrationality integrated in the spread of TQM? With these questions considered, this research, setting the diffusion of TQM as the case, aimed to uncover the truth and rules of the diffusion of a new management technique in Chinese context and to 
provide guidance and inspirations for how to introduce other foreign management knowledge in the future.

\section{Propositions and Hypotheses}

New management concepts were often raised by countries with relatively high management level. The term “TQM (Total Quality Management)” was coined by American scholar A. V. Feigenbaum in 1961 in his book, which was usually seen as an effective method for improving organizational performance. While the concept was raised in America, it was not paid much attention until Japan had achieved great success in quality management after Deming and Juran introduced TQM to Japan in the 1960s. Owing to the implementation of TQM in Japanese business, its products had imposed great threat to American products in the international market and America also began to have great interests in TQM study. America's demand for TQM study was largely caused by competition. In 1978, China made the great decision of reform and open up, and economy development had then become the urgent task. The economic growth was inseparable from the development in management, so China began to learn from foreign advanced management theory and practice as China hadn't formed its own systematic modern management system. TQM was one of the most important management techniques introduced in China. When TQM had just been introduced, China was still in the planned economy period and enterprises were just affiliates of the government who was responsible for every economic decision-making. At that time, the Chinese products were poor in quality and the traditional management skills wouldn't help the Chinese enterprises to produce good quality products competitive in the international market. Therefore, it was the government's demand to introduce TQM in China to improve its product quality and economy. In the late 1990s, China gradually transformed into a socialist market economy and enterprises were given much more freedom in making decisions, the demand for introducing management techniques would be influenced by technological factors or psychological conditions like legitimation. Therefore, the first set of propositions is assumed here:

Proposition 1: Demand is the main reason to cause imported-type management innovation.

Proposition 1a: The dominant body of demand for management innovation has gradually transformed from government to enterprise.

TQM was described as a management fashion. Carson (2000) [8] did a bibliometric research to collect and calculate certain publications on management fashion in America from the 1950s to the 1990s. He found that there were 16 management fashions emerged in that period and they had a bell-shaped life cycle lasting for about 10 years. TQM was recognized by him as the management fashion in the 1980s. Domestic scholar Bao Yuze et al. (2010) [9] also did a bibliometric analysis of domestic publications on management fashion and considered TQM was a management fashion imported during 1978-1984. Since the initial decision to introduce TQM was made by Chinese government, it took many efforts to import and disseminate it in China. In May 1979, Liu Yuanzhang and other Chinese scholars forming a team of 15 people were sent to Japan to learn the experience of TQM under the government's mission. Liu (2011) [10] mentioned that he had visited Japan and America to inspect and communicate for a dozen times in the latter ten years. Therefore, Chinese scholars were the first group of people in China to receive TQM theory and spread it to others. Since they had more expertise in knowledge, this paper deemed that they were more rational than others like the business managers. In the period of market economy, companies were free to choose their management skills but also vulnerable to the influence of their internal and external environment, thus leading to the irrational side of management fashion. Based on the perspective of rationality, a set of hypotheses are proposed here below:

Hypothesis 2: The diffusion of management innovation initiated by different bodies shows difference in rationality.

Hypothesis 2a: When government is the initiator of management innovation, it shows rationality at the early stage, but irrational features emerge in the later stage.

Hypothesis 2b: When enterprise is the initiator of management innovation, it shows irrationality at the early stage, but rational features emerge in the later stage.

The national policy of reform and open up was closely related to the state leader Deng Xiaoping, and he often stressed that China should actively absorb the wisdom in western science, technology, management and art (Zuo Ling, 2013 [11]). Chinese government and scholars had made great efforts to improve the backward situation of management level in China. Since original management innovation requires a certain accumulation of knowledge, it often emerges in western countries where they have solid base in management science and mature market economy. In the 30 years after 1978, both the economic system and the dominant body of demand for 
management innovation had changed, presumably, the diffusion life cycle of management innovation in Chinese context should be different from the western countries. In the period of planned economy, enterprises were stateowned and the implementation of management innovation was forced by guidance documents and laws enacted by government. Later in the period of market economy, the ownership of enterprise was various, and most enterprises can decide by them self whether they wanted to adopt certain innovations. From the analysis, another set of hypotheses are raised here:

Hypothesis 3: The diffusion of management innovation initiated by different bodies shows different features in life cycle.

Hypothesis 3a: When government is the initiator of management innovation, it spreads faster and declines slower and its influential area is smaller.

Hypothesis 3b: When enterprise is the initiator of management innovation, it spreads slower and declines faster and its influential area is larger.

\section{Research Methods and Results}

To get insight into the diffusion of TQM in China, this paper did a bibliometric analysis of publications on TQM in Chinese largest online literature database CNKI. Bibliometric method had been frequently used in the study area of library and information science. This method combined mathematical and statistical knowledge together and can analyze quantitatively the distribution features and trends of literatures. Because the release date and capacity of journals are relatively fixed, and the papers published on journals are easy to be retrieved and counted, they are often selected as the target of measurement in bibliometric methods.

This research collected papers from certain journals published from 1978 to 2014 on TQM in China. In order to get more accurate and representative data, this paper had chosen 129 journals in total as research targets, and whether in the span of time or in the number of journals selected, this research had surpassed previous studies. The 129 journals were divided into three different categories (each category includes 43 journals): academic, semi-academic and non-academic. The criterion for classifying a journal as "academic" is whether or not the journal has been ever included in CSSCI (Chinese Social Sciences Citation Index) which is the most influential academic index in Chinese social science study. The criterion of "semi-academic" was some Chinese core journals which have never been included in CSSCI, and the remaining general public journals were classified as "non-academic" or public. Since most journals were established and closed in different time, this paper took the starting and ending time in CNKI as reference for calculation. When choosing the search term, this paper argues that TQM and TQC (Total Quality Control) are the same. In Japan, these two terms were used interchangeably. Therefore, this paper selected “Total Quality Management” or “Total Quality Control” or “TQM” or "TQC” as the search term to check them in "Subject" or "Title" or "Key Words" or "Abstract" and recorded the number of articles published each year in a specific journal. Then, the total number of articles published in a year was divided by the number of journals to obtain the average number of articles published per year in each journal. Because the final average number calculated was small, the data was standardized for better observation and comparison. According to the final data, two line charts were drawn through Excel here. Chart 1 is the publication conditions of TQM on three different categories of journals, while in Chart 2, the three different data were added up to indicate the overall trend of publications on TQM in China.

\section{Analysis of Results}

\subsection{Demand}

Demand is a commonly seen term in economy. When China decided to develop its economy in 1978, it demanded to establish a modern scientific management system because the traditional Chinese management skills wouldn't match with modern enterprises and companies. After experiencing the Cultural Revolution, China didn't have the ability to start original management innovation, so it had a demand to import from the outside world. This demand of development was fully realized by the government who was the decision maker in economy and it took many effective measures to compulsorily promote TQM in China like setting TQM office in enterprises, encouraging the formation of QC groups, establishing national quality awards and enacting laws. Through these measures, as shown in Chart 2, the discussion on TQM rose rapidly in the first two years. The government's demands to enhance the quality of domestic products and improve management level were the driving forces behind the heated discussion. 


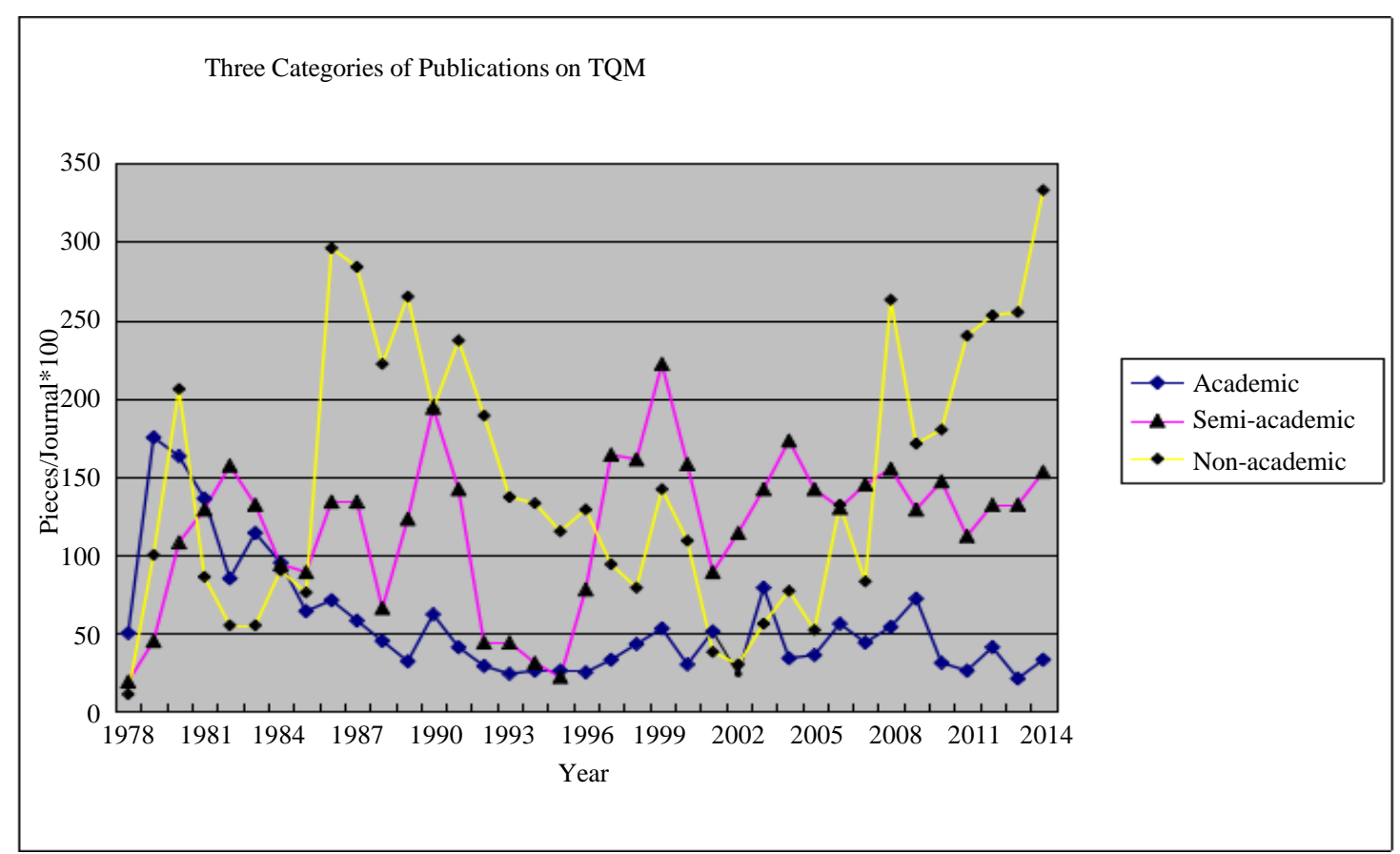

Chart 1. Three categories of publications on TQM from 1978 to 2014.

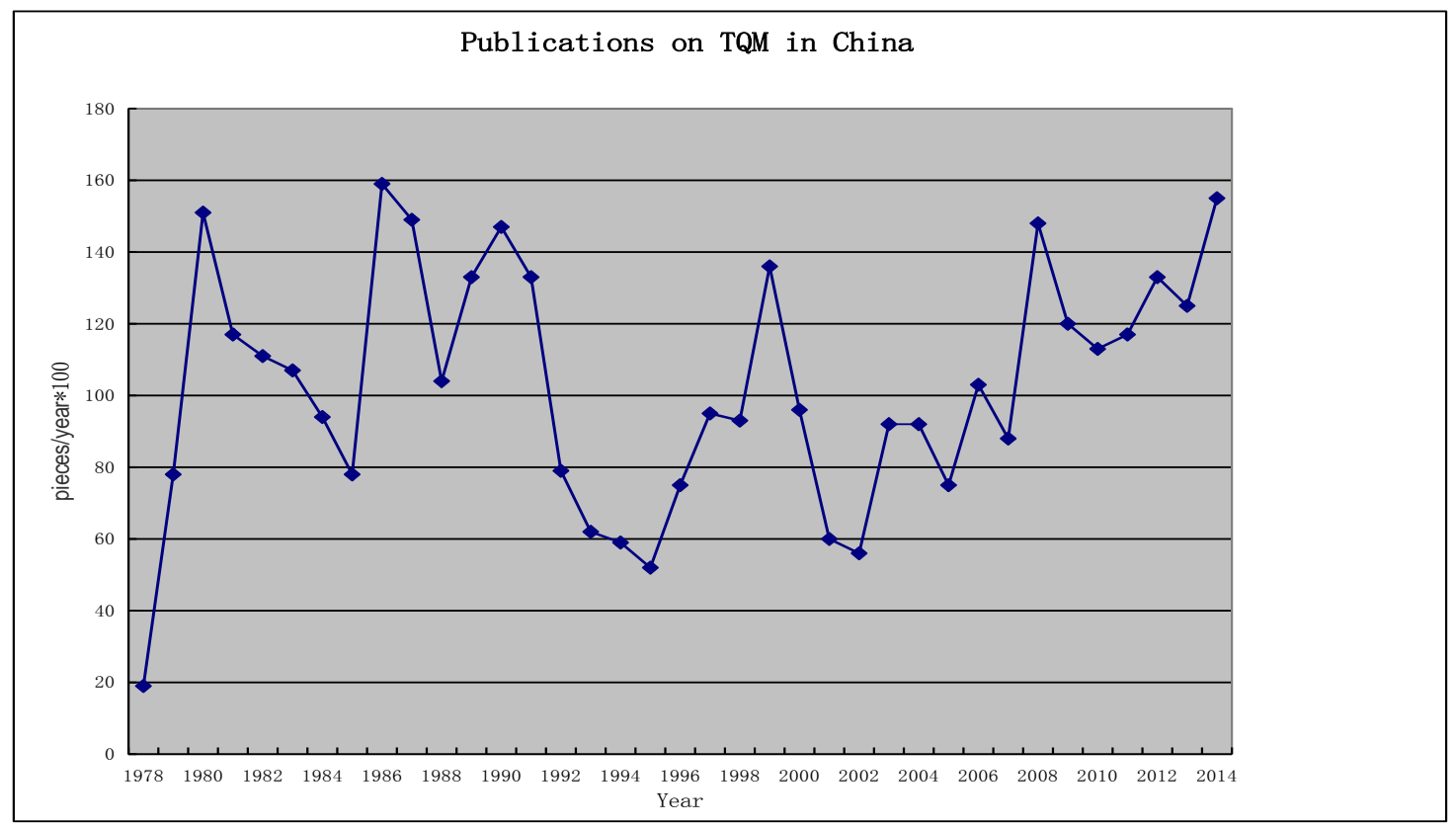

Chart 2. Publications on TQM from 1978 to 2014 in China.

In 2001, when China joined WTO, non-state-owned enterprises had obtained dominant position in the market economy, and the technology and management of enterprises had also improved significantly compared with the past. However, researchers studying in Chinese management pointed out that the rich experience of China's rapid economic development and management practices had barely contributed to the generation of any influential management theory in the world. Chinese original management innovation was rare and lacked influence. In addition, the management discipline in domestic higher education was to teach western management science. Chinese management research wasn't taken seriously until recent years by domestic scholars. Therefore, consi- 
dering the intense competition in the market and the weak management knowledge in China, enterprises should have a large demand for management innovations. Previous studies also showed that China had introduced knowledge management, TQM, six sigma, management by objectives and so on from abroad in this 30 years. Through the above analysis, we can conclude that demand caused Chinese government and enterprises to import management innovations and proposition 1 and $1 \mathrm{a}$ are consistent with China's reality.

\subsection{Rationality and Irrationality}

Daniel A. Wren (2008) [12], in his book The History of Management Thought, had classified two stages on the evolution of management: "the scientific management era" characterized by rationality and "the social person era” by irrational factors. Management is both a science and an art. Rationality and irrationality coexist in this area. The irrationality is often connected with "human” factors while rationality emphasizes objectivity and logic. Most researches regard management innovation as the rational behavior of organizations, however, from a fashion perspective, people’s psychological activity and social factors also play an important role.

we have known that the early spread of TQM was led by government and its dominant position in economy have lasted from 1970s to early 1990s. From Chart 1, we can see that in this period publications on TQM first reached its peak in academic journals, followed by non-academic journals the second and semi-academic journals the last. This shows that the discussion on TQM was started by academic scholars and the public accepted it very quickly after all the powerful measures taken by the government. Since we deemed that academic scholars were more rational than the public, the early diffusion of TQM was more rational and the rationality was embodied in their objective to improve product quality and their attitude to adapt TQM to the practical condition of China in implementation. In the late 1980s (see Chart 1), when the academic discussion on TQM has declined to a very low level, the public discussion on it experienced a sharp rise from 1985 to 1986 . This indicates that rational discussion on TQM wasn't continued in the latter time and the public's loud voice replacing the academic analysis brought irrational factors to TQM. Between 1986 and 1987, the International Organization for Standardization issued the ISO9000 quality certification standards, and Chinese government also promoted quality certification in China to further warn people the importance of quality, but it was regarded as guarantee of product sales among some enterprises. Therefore, many companies quickly abandoned TQM under the table the moment they acquired the quality certification, as we can also see in Chart 1 that from the late 1980s to 1990s the public's enthusiasm on TQM showed a trend of decline. This indicated that these companies were having an irrational perception on the function of certification. From the above analysis, Hypothesis 2a can be proved.

In 1992, to establish socialist market economy was put forward by the National Congress and enterprises gradually acquired the dominant position in management innovation. It shows in Chart 1 that the publications on TQM of all the three journal categories have reached their peaks in 1999 after 1992, which indicates that rationality and irrationality have both increased at the same time. After China joined WTO in 2001, China's market economy was greatly deepened. It can be seen in Chart 1 that from 2005 the academic discussion on TQM keeps fluctuating within a certain small range while the public's discussion shows an obvious upward growth trend, which means irrationality increased during this period. The public's great enthusiasm about TQM in the 21 century coincided with some big food quality and safety problems exposed in China, such as the poisonous food additive "Sudan dyes" in 2005 and the tainted milk powder event in 2008 etc. We discovered in Chart 2 that the discussion on TQM rose quickly when such serious quality accidents happened. From the above analysis, we can conclude that when enterprises were in the dominant position, rationality and irrationality coexisted in the early stage and irrationality increased in the later stage. Thus, hypothesis $2 b$ can't be proved but hypothesis 2 is still supported.

\subsection{Life Cycle of Diffusion}

The 37 years after 1978 can be divided into two stages on 1992. Before 1992, planned economy was dominant, and after 1992, market economy gradually replaced the planned economy. As we can see in Chart 2, TQM has experienced three times of "boom and bust" processes before 1992. In addition, we observed that their life cycle was not in a symmetrical bell shape, it took more time to decline than to increase. Government's imperative administrative interference in TQM implementation was considered the reason behind the situation because it can guarantee high promotion efficiency and restrain enterprises from retreating. In the early 1980s, extreme supply 
shortage of goods was the condition in China and all the goods produced no matter good or bad can be sold out. It was quantity not quality that was in the first consideration of enterprises. The quality awareness between the government and the enterprises were not at the same level, so even some enterprises didn't want to implement TQM, they can't retreat from it easily during this period. That's the reason why we can see in Chart 2 that in the early stages TQM spread faster and declined slower.

After 1992, the market economy was gradually established and enterprises acquired autonomy in management. From Chart 2, we can see that the discussion on TQM experienced an obvious process of rise and fall from 1995 to 2002 and the decline of discussion took much less time than the rising. Later, from 2002 to 2014, the discussion on TQM shows an upward fluctuation trend in Chart 2 in general. It was inferred previously that the diffusion life cycle of TQM in Chinese market economy would be like the bell-shape curve of management fashion like in other market economy countries. However, from the curve we obtained in Chart 2, the diffusion of TQM in China experienced more complex fluctuations. Besides, from the information collected from other literatures, we found that TQM was mainly applied in some state-owned enterprises of certain light and heavy industries like textile, automobile, steel and so on before 1992. However, after 1992, TQM was applied in almost every industry, which indicated that TQM displayed greater influential power in market economy. Through the above analysis, hypothesis 3 , 3a and $3 \mathrm{~b}$ can be tested right.

\section{Conclusion and Discussion}

About 37 years have passed since the reform and open up. However, the condition that Chinese management innovation still depends on introducing and absorbing foreign management theory is not much changed. This paper tried to reveal the diffusion features of the imported-type management innovation in Chinese context with TQM as the research case. The study found that in different period after 1978, the initiator, rationality and diffusion life cycle of management innovation showed great differences. This indicates that to study management innovation in different contexts is significant because it is beneficial to the development of domestic management science. Our management research had always been strongly influenced by western management studies and Chinese scholars had very little contribution to original type management innovation in the world, which are also the predicament faced by Chinese management research. In recent years, the call for developing Chinese management study is strengthened. Although the enterprises have replaced government to be the initiator of management innovation, whether they can stay rational was uncertain. From previous study of management fashion, enterprises may just "jump on the bandwagon" in applying certain new management skills. Therefore, academic scholars of management should join public discussion and keep an eye on the demand of enterprises in practice. From Chart 1, we can clearly see that academic discussion on TQM only peaked once in 1979, and when the public had keen interests in it in the later time, the academic discussion on TQM had cooled down, which indicated that the academic research had been divorced from the real needs of management practice. To extract essence from Chinese management practices would be the future direction of Chinese original management innovation.

\section{Project Support}

This research is sponsored by the National Social Science Foundation (Grant No.: 12BJY106) and the Ministry of Education (Grant No.: 11YJC790002).

\section{References}

[1] Schumpeter, J.A. and Opie, R. (1961) The Theory of Economic Development. Harvard University Press, Massachusetts.

[2] Stata, R. (2004) New Ways to Evaluate Innovative Ventures. MIT Sloan Management Review, 45, 96.

[3] Li, Z.N. and Lu, C.Y. (2002) The Quantitative Analysis on Contribution of Management Innovation to the Economic Growth. Journal of Tsinghua University, 17, 25-31.

[4] Bao, Y.Z., Tan, L.W. and Wang, L. (2013) A Review of the Literature of Management Innovation and Future Prospects. Foreign Economics \& Management, 35, 43-50.

[5] Su, J.Q. and Lin, H.F. (2010) Review on Research Perspectives of Management Innovation and Prospects. Chinese 
Journal of Management, 7, 1343-1349.

[6] Brikinshaw, J. and Hamel, G. (2008) Management Innovation. Academy of Management Review, 33, 825-845. http://dx.doi.org/10.5465/AMR.2008.34421969

[7] Abrahamson, E. (1996) Management Fashion. Academy of Management Review, 21, 254-285.

[8] Carson, P.P., Lanier, P.A., Carson, K.D., et al. (2000) Clearing a Path through the Management Fashion Jungle: Some Preliminary Trailblazing. Academy of Management Journal, 43, 1143-1158. http://dx.doi.org/10.2307/1556342

[9] Bao, Y.Z., Tan, L.W. and Liu, L.Q. (2010). Multiple-Cases and Bibliometric Study on Management Fashion’s Dissemination in China. Journal of Intelligence, 29, 22-26.

[10] Liu, Y.Z. (2011) My Quality Life Career. Science Press, Beijing.

[11] Zuo, L. (2013) Deng Xiaoping's Vision of Western Culture and Contemporary Value. Research on the CPC’s History and Building, 10, 87-92.

[12] Wren, D.A. (2005) The History of Management Thought. John Wiley \& Sons Inc. 